Fecha de recepción: abril 2021

Fecha de aprobación: mayo 2021

Fecha publicación: junio 2021

\section{Symbiotic Design and Natural Systems. Biotechnical Methodologies and Biomorphic Methodologies}

\author{
Paulo Parra ${ }^{(1)}$
}

\begin{abstract}
How operational knowledge are extracted from biological systems and applied rigorously in project practice? Can we speak of biological methodologies, that is, of projectual methodologies of nature? And can these methods be applied in technical methodologies? Is there a technological evolutionism just as biological evolutionism? Nature has always been, in multiple ways, a source of inspiration for man. However, according to the author, there are two fundamental approaches to these uses that should be distinguished here. They are, on the one hand, a more structural and functional approach, such as Bionics and Structural Morphology, for which the name Biotechnical Methodologies is proposed and, on the other hand, a more formal approach, as are Streamlining and Biodesign cases, for which the name Biomorphic Methodologies is proposed. These two methodologies are fundamental in the definition of "Symbiotic Design", which aims to identify the symbiotic processes applied by biological systems and to propose them as important elements in the integrated design of technological systems. In this view, the relationship between human beings and objects is proposed as a symbiotic system, in which Design assumes itself as a hinge element. This cosimbiosis, allowing intimate cooperation, reduces the distance between biological systems and technological systems and provides a new project unit for the 21st century.
\end{abstract}

Keywords: Symbiotics - Biological evolutionism - Technological evolutionism - Design Organic Functionalism - Bionics - Biomorphic Design - 21st century

[Abstracts in spanish and portuguese at pages 149-150]

(1) Paulo Parra tiene una carrera multifacética como diseñador, docente y coleccionista. Con trabajos en las áreas de Diseño de Producto, Transporte y Arquitectura, Diseño de Exposiciones, Diseño de Comunicación e Interfaces y Diseño Estratégico, también desarrolló actividades como comisario, museólogo, investigador y conferencista. También diseñó el soporte para barricas de vino a Adega Mayor, edificio diseñado por el arquitecto Álvaro Siza Vieira y diseñador invitado por “Art on Chairs" para proyectar una silla para el presidente de la Comisión Europea. Como catedrático, fue Jefe del Departamento de Diseño Industrial de la Facultad de Bellas Artes por el cual es Doctor en Diseño y donde actualmente es Profesor Asociado con Agregación, Coordinador del Núcleo de Investigación en Diseño y miembro de la Senada de la Universidad de Lisboa. Fue el padrino del doctorado honoris causa de António García por la misma universidad, y también fue 
Director de Diseño de tres escuelas superiores más; ESAD de Matosinhos, IADE de Lisboa y Universidad de Évora. Como investigador, Paulo Parra ha publicado libros y artículos regularmente desde 1988, además de haber establecido una Colección de Diseño titulada "Iconos y Clásicos del Diseño" con más de 3.000 objetos de diseño internacional y 600 del diseño portugués. También instaló y dirigió el Museo del Diseño - MADE. Su obra se mostró en exposiciones en varios países de Europa, Asia y América y también estuvo representada en "Expo Internacional de Zaragoza" (2008, España) por invitación oficial del Pabellón de Portugal.pauloparradesign@gmail.com

\section{Biotechnical and Biomorphic Methodologies}

Indeed, it is a given that nature and the systems used by it have been a reference for human beings throughout its history. Initially, this attitude was essentially mimetic, that is, what is commonly called Biomimicry and Biomorphism -imitation or formal inspiration of nature- and which, more recently, gave rise to proposals applied to design such as Art Nouveau, Streamlining or Biodesign. For these latter methodologies, as mentioned, the author proposes the designation of Biomorphic Methodologies - in the sense of grouping all methodological proposals that committed to analyze natural systems, living or non-living, which in a direct or indirect way, contribute to the aesthetic and formal evolution of objects and systems of man-made objects.

But also, progressively and above all following the technological evolution, another form of inspiration appeared in nature, no longer only at the level of the forms, but at the level of a deeper understanding of natural systems, that is, at the structural and functional level. These methodologies base their project praxis in Technical Biology, analysis of technical systems developed by natural systems. These proposals were based on the concept of biotechnology proposed in the 1920s by authors who argued that, if nature had experienced structural, mechanical, chemical and electrical solutions over thousands of years -an "engineering of nature"1-, it could, after carefully studied, be adapted and used in the design of technological systems.

In this sense, and as we will see, the first systematic demonstration of the application of Biotechnical Methodologies, according to the author, was developed by Leonardo da Vinci whose methodological process is analyzed in the chapter "From Technical Methodologies to Biotechnics", in proposals ranging from the study and dissection of animals until the study of complex phenomena of hydrodynamics and aerodynamics. Many other proposals for using these methodologies have since been developed. However, it was only at the end of the 19th century and the beginning of the 20th century that they acquired a greater systematization, with a perfectly defined and structured theoretical body, especially by some German authors in the 1920s and 1930s.

More recently, for project studies in this area, new disciplines have been developed and applied, such as Structural Morphology ${ }^{2}$, in the faculties of architecture and engineering, and like Bionics, in Design faculties. For this structuralist and functionalist vision, also 
with several methodological proposals, such as Organic Functionalism, Biotechnics or Bionics, the author proposes to use the term Biotechnical Methodologies - in the sense of grouping all methodological proposals that in a more rigorous and scientific way, they propose to analyze the natural technical systems, living or non-living, transporting them to the projectual culture in the perspective of producing technical or technological systems of greater or lesser complexity.

\subsection{Biotechnical Methodologies: Organic Functionalism and Bionics}

The idea that an object beauty depends on its usefulness and efficiency is responsible for initiating a new philosophical view on material culture. Among the first functionalists, there is the German architect and urban planner Friedrich Weinbrenner (1766-1826), who writes in his work Architektonisches Lehrbuch, published between 1810 and 1819: "Beauty is in the total agreement between form and function"3. Composed by a group of three books, this work is published in Germany and especially aimed at students of Art and Architecture - "Geometretrische Zeichnungslehre" from 1810, "Perspektivische Zeichnungslehre" from 1817 and "Uber die hohere Baukunst" from 1919. The contents of Architektonisches Lehrbuch would later be complemented by two additional essays: "Uber architektonish Verzierungen" from 1820 and "Uber die Saulenordnungen, den Gebrauch der Saulen, die Eintheilung, Anordnug and Ausfuhrung der Gebaude" from 18254. One of the aspects that stands out in these writings is the fact that they examine the problems of the relationship between "form and function" in architecture based on the examples of objects in current use. Also, it is likely that the statement by F. Weinbrenner, previously quoted, inspired the maxim "Form follows function", passed on too many generations of designers and architects, and that this, in turn, was inspired by the work of J.B. Lamarck ${ }^{5}$. Friedrich Weinbrenner, Professor and architect, was born in Lehrjahren in 1766. He was "construction director" of the Grand Duchy of Baden, between 1801-1826, the main architect and urban planner in the city of Karlsruhe, and the first German architect of the 19th century to be internationally recognized. His planning for the city of Karlsruhe - including the design of buildings, such as palaces, churches, synagogues, government buildings, city gates, shops, fountains, theaters, arms depots, cemeteries and farms - is a remarkable achievement. Its disciplinary intersection in fields as diverse as mythology, aesthetics, the history of culture and society, the history of art, geometric design and perspective, structures and materials, architectural composition, management of construction and building costs and above all, the domain of scientific theories of the time are based on the new rationalist models that were extremely influenced by the scientific movement of the 19th century.

The example of this is confirmed when F. Weinbrenner assumes the direction of Baugnade or "construction direction" of the Grand Duchy, to bring about social improvements through the reform of aesthetic paradigms. He announces that whoever builds according to municipal parameters, considering factors such as location, height, number of facilities, among other things, will receive a fixed economic fee. In 1815, he presented the final version of the standard construction document, in which three type houses were designed 
according to their location and economic class of destination ${ }^{7}$. Also, regarding the issue of urban planning, namely due to the consideration of the safety factor, F. Weinbrenner imposes specific construction rules: the buildings should have at most a height equivalent to the width of the streets; the doors should open into the houses and not out; woods used in the interior should be at least about ninety centimeters away from any flame producer ${ }^{8}$. This German architect is one of the precursors of functionalism. His ideas about beauty accentuate his agreement with the function. As the author refers, on page 6 of the third volume of Lehrbuch, "Uber die hohere Baukunst", the author refers to beauty as übereinstimmung der form mit dem zweck, that is, in the total agreement between form and function, giving examples of functional objects of everyday life. But his concept of beauty is not limited to the simple satisfaction of purposes, since it also includes adequacy and usefulness ${ }^{10}$, transforming Friedrich Wienbrenner into one of the first great references of functionalism. Another renowned functionalist author was Horatio Greenough (1805-1852), an American sculptor who lived in Italy between 1829 and 1851, the date on which he returned to the U.S., where he would pass away the following year. Considered, along with Friedrich Wienbrenner ${ }^{11}$, one of the first functionalists, he published his ideas about the evolution of the arts, architecture and design in the work entitled The Travels, Observations, and Experience of a Yankee Stonecutter ${ }^{12}$. His theories about functionalism were adopted at the end of the 19th century and early 20th century by architects and designers, such as Louis Sullivan and Ludwig Mies van der Rohe. The comparison made by H. Greenough between the evolution of design and biological evolution was a precursor and would influence numerous later authors.

His observations about the functioning and suitability of natural systems, with their respective transposition to artificial systems are notable: “(...) observe the skeletons and skins of animals, through the variations that go from the beast to the bird, from the fish to the insect, are we not impressed by its variety and beauty? There is no arbitrary law of proportion and no rigid model of form"13. Defending that: "The law of adaptation is the fundamental law of nature in all structures"14, years before the publication of the Origin of Species, he criticized the domain of arbitrary rules of taste, installed in everyday objects. As he said: "Many works are more beautiful without ornament"15. And he adds: "When I define Beauty as the promise of Function; Action as the presence of the Function; As a function record, I arbitrarily separate what is essentially one"16.

Defender of the function, he found in shipbuilding the exemplification of his theoretical proposals. "Watch a boat in the sea! Notice the majestic shape of its hull as it advances through the waters, observe the graceful curvature of its body, the gentle transition from the curved to the flat, the firmness of its keel, the launch of its bowsprit, the symmetry and rich outline of its masts and risers, and those big wind muscles, the sails!" ${ }^{\prime 7}$. The analysis of the characteristics of shipbuilding will then be proposed as an example to be followed in civil construction (See Figure 2): "We could transfer to civil architecture the responsibilities that weigh in shipbuilding and we would have long buildings superior to the Parthenon for the purposes for which they were intended (...)"18. Anticipating all pedagogical theories of design, he says: "I wish to see normal schools of structure and ornament working, organized in a simple but effective way, and constantly busy in designing for manufacturers, and for all mechanics who need guidance aesthetics in your operations"19. 


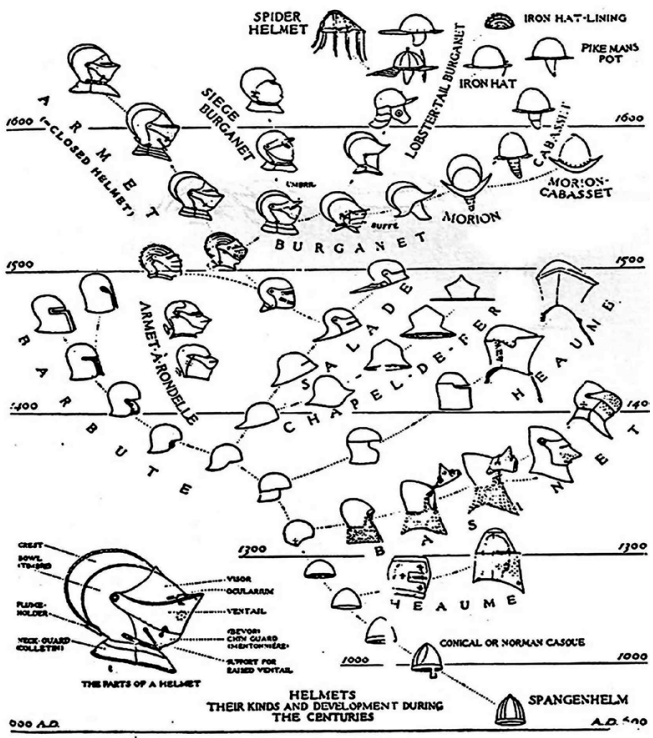

Figure 1. Above:

Helmet evolution by Bashford Dean

(1915). Below:

Comparative evolution of brain volume from Chimpanzee to Modern Man.

Figure 2.

Brontosaurus skeleton and bridge structure on South Grand Island, New York. Analogy established by Alan Powers, in Nature in Design (1999).

1
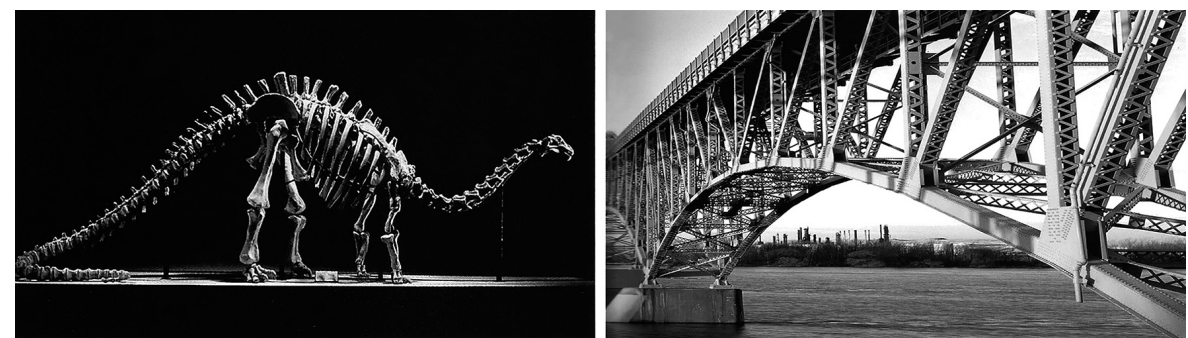

2

But H. Greenough goes even further in defending a progress notion associated to function: "If you go through the various stages of a boat development, from the canoe dug in the trunk of the tree and the old galley, to the latest types of corvettes, we will note that any progress in performance has been a progress in composition, beauty or grandeur, in accordance with the function of the vessel" ${ }^{20}$. In this statement, the author advocates a 
technological evolution because, as already noted, the term progress was used to refer to the evolution in technical systems. As R. Lewontin and R. Lewis refer in the introduction to their article on Evolution: "Although the concept of evolution has been firmly identified with organic evolution, the history of living organisms on Earth, the theory of the evolution of life is just a special case of a more general view of the world, which can be defined as evolutionism" 21 .

That is, before being a scientific theory, evolution was an ideology, it proposed a global view of the changing world. In the 18th century, August Diderot, author of the Encyclopédie, stated: "Everything changes, everything passes, there is nothing but everything that remains"22. A natural static ideology typical of the feudal system in which owners and servants were attached to the land, was gradually being replaced by a theory that considered change as natural, that is, by an evolutionary vision, better suited to the rise of the classes of traders, financial and later industrial. But between the agricultural revolution (associated with land) and the industrial revolution (associated with production) another revolution had to exist, the commercial and financial revolution (associated with exchanges) in which movement was a crucial factor. As Friedrich Engels says in the 19th century: "Movement, in the most general sense, understood as the mode of existence of matter as its inherent attribute, comprises all the changes and processes that occur in the universe, from the mere change of place to thought" 23 .

But change is not enough, as Alfred North Whitehead says: "There can be meaningless change and no progress" 24 . The term progress would therefore be more appropriate, and James Ferguson, an English writer and scholar, in his book An History Inquiry into the True Principles of Beauty in $\mathrm{Art}^{25}$, published in 1849, dedicated a chapter to the theme with the name "Progress of Art", in which, in this thematic perspective, refers to the evolution of ships as follows: "We have a constant progress (of ships) over eight centuries, and it will be difficult to calculate how many millions of people, not only in each port of the Europe, but also in America, were necessary to produce this great result"26. Ship design is often referred to as an example in rationalist literature as it is strongly illustrative of progress in terms of technical systems, in the same way that variations in the Gothic cathedral are a reference in studies that focus on progress in architecture. Technological progress manifests itself in all areas: in terms of engineering, in the construction of bridges, in agriculture, in the mechanization of processes, etc.

As P. Steadman points out, more than a great leap resulting from a brilliant inventor, the great progress was due, for millions of years, mainly to the work of anonymous artisans and mechanics who with their combined efforts were responsible for small and sequenced progress ${ }^{27}$. These notions of progress and evolution of objects appear perfectly visible in the illustrations by A-H. Pitt-Rivers on the evolution of the boomerang, of 1906 - whose precursor work was previously referred to in the article "Orthogénesis of the Tools" - in Bashford Dean's on the evolution of the helmet, of 1915 (c.f. Figure 1) and, more recently, in Le Corbusier's 1921 evolution of the automobile (See Figure 3). 

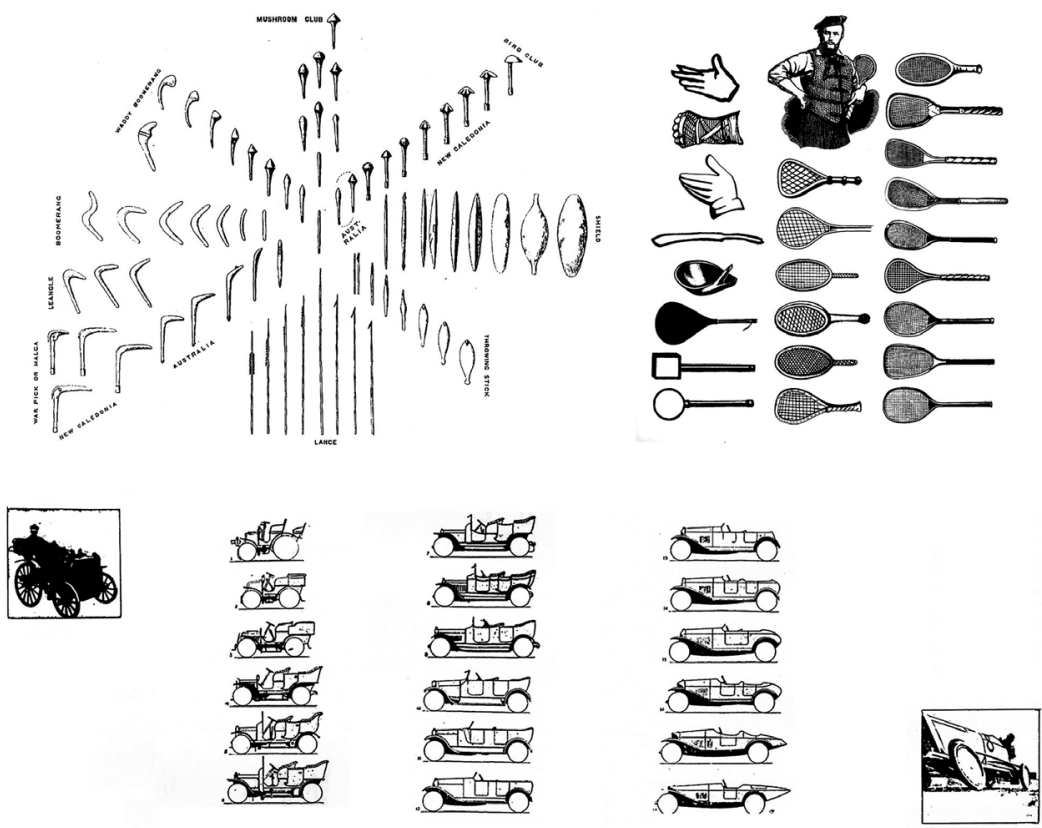

Figure 3. Evolution of some types of objects: "boomerang” by Pitt-Rivers (1906), tennis racket (author and year of unknown design) and automobile by Le Corbusier (1921).

The study of social systems also presupposes evolutionary theories, as we have already seen. As R. C. Lewontin and R. Lewis refer: "The evolutionary theories of social systems, namely Marxism and some of its variants, are explicitly progressive and perfectionist" 28 . And then they add: "And the stories of religion, philosophy, science, fine arts, industrial techniques, show the existence of a succession of states". That is, in modern theories of evolution, C. Darwin was a culmination and not its origin. C. Darwin himself, in fact, in the third edition of Origin of Species of 1861, makes a historical outline of the writings that preceded his, on organic evolution ${ }^{29}$.

Basically, the evolutionary analogies of H. Greenough or J. Ferguson, among others, predate the publication of the Origin of Species, thus demonstrating the existence of the genesis of an evolutionary theory of technology and a notion of progress related to systems or technological organisms, even though, in this case, the reference to "evolution", as defended by P. Steadman, refers more strictly to the sense of "progress" or "development" As H. Spencer -the greatest defender of evolutionary progress in the 19th century- says in Progress: Its Law and Cause, 1857: "From the first traces of cosmic changes to the last 
results of civilization, we find that the transformation of the homogeneous into heterogeneous is what progress essentially consists"30.

The functionalist vision of $\mathrm{H}$. Greenough marked proto modernism by proposing "beauty as a function commitment". In the book Form and Function - Remarks on Art by Horatio Greenough, the editor says on the back cover: "It was Greenough, not Walt Whitman, who first protested the lack of meaning in ornamentation. It was Greenough, not John Ruskin, who first expressed the idea that a people's buildings and art express their morality. It was Greenough, not Le Corbusier, who first said that buildings primarily for use "could be called machines". It was Greenough, not Louis Sullivan, who first spelled out the principle that, in architecture, form must follow function." But as we noted earlier, it was not $\mathrm{H}$. Greenough but F. Weinbrenner who first said that form must follow function. This important German author owes the maxim of functionalism. But perhaps even more important and less publicized in the work of $\mathrm{H}$. Greenough, are his proposals for the analysis of natural structures intended for later application in artificial systems, anticipating future biotechnological methodologies. Later, this will be a great step in methodological and scientific consolidation of the referred processes of analysis of the natural structures. The Origin of Species would be crucial for the understanding of biological evolutionism and for the consequent creation of a support base for the development of technological evolutionism, this one previously explored based on Lamarkian theories, closer to the adequacy to technological systems. However, it is very important to keep in mind that this work by C. Darwin was published seven years after the death of $\mathrm{H}$. Greenough, which is to say, seven years after the edition of his book The Travels, Observations, and Experience of a Yankee Stonecutter. H. Greenough's work remains in history as a reference of functionalism, extremely important in the evolution of project culture and biotechnological methodologies. Also a forerunner in the analogies established between nature and art is the work of Reverend John George Wood, published in Boston in 1875, with the suggestive title Nature's Teaching's: Human Invention Anticipated by Nature ${ }^{33}$ (See Figure 4), where the author, using different areas of human knowledge ordered by chapters such as "nautical", "hunting and war", "architecture", "utensils", "optics", "utilitarian arts" and "acoustics", seeks to demonstrate that prototypes found in nature can help concretize human productions. This manual is probably the first comprehensive survey of comparisons between biological and technical systems, with about 750 illustrations that help to understand the analogies advocated by J. Wood.

One of the most famous examples he mentions in architecture is the Crystal Palace designed by Joseph Paxton and inaugurated for the Great Exhibition of 1851. Inspired by the leaf ribs of the giant water lily Victoria Regia ${ }^{34}$, it is a good example of Structural Morphology (See Figure 5). But hundreds of other examples appear in his work, establishing analogies between examples taken from Biology and human production.

Another reference work and perhaps the first to use the term "Biotechnics" is the book by the German Raoul Francé, Die Planze als Erfinder (Plants as Inventors), published in Stuttgart in 1920. According to him, all forms of nature are a product of natural selection and a consequence of functions developed by organisms in their adaptation, that is, their forms are the solution to solve problems that biological systems encounter. In this sense, R. Francé proposes that anyone looking for a technical solution, should study "biotech- 